\title{
METRÓPOLE E FANTASMAGORIA ${ }^{1}$
}

\author{
Paulo Roberto Teixeira GODOY²
}

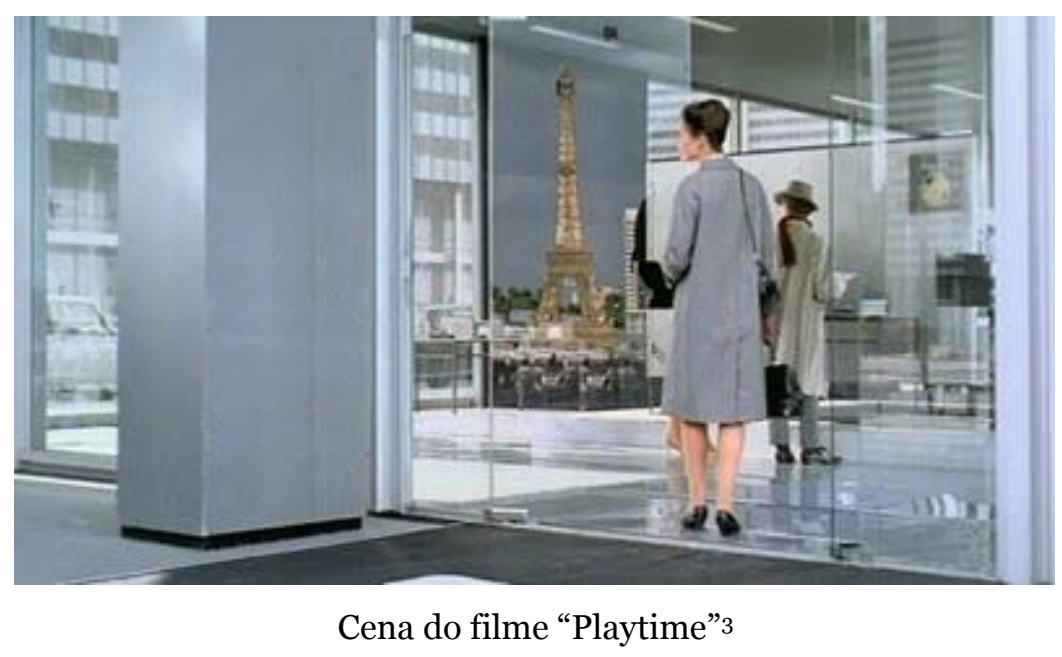

\section{RESUMO}

A intenção principal deste artigo consiste em apresentar a metrópole e suas fantasmagorias como meio de reafirmar a contribuição da teoria marxiana do valor e do fetichismo, desenvolvidas por Karl Marx e Walter Benjamin, para a investigação do processo de valorização capitalista do espaço-mercadoria em sua expressão real e contraditória que é a metrópole capitalista. O objetivo, portanto, está em elucidar as determinações sociais e históricas de sua existência em um modo específico de produção e reprodução social.

Palavras-chave: Valor. Espaço. Metrópole. Fantasmagoria.

\section{METROPOLIS AND FANTASMAGORIA}

\begin{abstract}
The main intention of this article you present the metropolis and their phantasmagoria as a means of reaffirming the contribution marxian theory of

\footnotetext{
${ }^{1} \mathrm{O}$ presente artigo consiste em resultado parcial de Auxílio à Pesquisa/Fapesp/2017-2019. Texto apresentado em palestra realizada no II Congresso Brasileiro de Organização do Espaço (II CBOE) e XIV Seminário do Programa de Pós-Graduação, realizado na cidade de Rio Claro/SP, entre os dias 24 a 28 de março de 2019, intitulado "Soberania e Ciência no século XXI: a decolonialidade do saber como novo paradigma geográfico?".

2 Professor Assistente Doutor do Departamento de Geografia e do Programa de Pós-Graduação em Geografia da Universidade Estadual Paulista (UNESP) - Rio Claro. E-mail: p.godoy@unesp.br

3 Playtime (1967). Produção: Bernard Maurice com Specta Films. Roteiro: Jacques Tati com colaboração de Jacques Lagrange. FOLEGATTI, Luiza G.; SCHIAVINATTO, Iara Lis F. As Cidades de Jacques Tati: novas relações sócio-técnicas presentes na década de 50. São Paulo: Codis - História, Arte e Cidades, no 6, jan./jun, 2011, p. 333-366. Imagem: Fonte: I’ve Started Something.
} 
value and fetishism, developed by Karl Marx and Walter Benjamin, for the investigation of the capitalist valorization process from the space-merchandise in its real and contradictory expression which is the capitalist metropolis. The objective, therefore, is to elucidate social determinations and historical of its existence in a specific mode of social production and reproduction.

Keywords: Value; Space; Metropolis; Phantasmagoria.

\section{METROPOLIS ET FANTASMAGORIA}

\section{RESUME}

La intention principal de cette article est de présenter la métropole et le vôtre fantasmagorie comme moyen de réaffirmer la contribution de la théorie marxiste de la valeur et du fétichisme, développée par Karl Marx et Walter Benjamin, pour l'investigation du processus de valorisation capitaliste de espace-marchandise dans son expression réelle et contradictoire qu'est la métropole capitaliste. L'objectif, est donc, d'élucider les déterminations sociales et historiques de son existence dans un mode spécifique de production et de reproduction sociale.

Mots clés: Valeur; Espace; Métropole ; Fantasmagorie.

\section{VALOR E ESPAÇO}

A abordagem geográfica do processo de espacialização do valor e do curso histórico do desenvolvimento do modo capitalista de produção implica, necessariamente, a interpretação das escalas geográficas do movimento espacial do capital e da força de trabalho na configuração da divisão social e territorial do trabalho, bem como dos conflitos políticos e da luta de classes no âmbito das regiões e das disputas territoriais. Nesse sentido, o lugar torna-se fundamental à análise e interpretação das formas singulares que assumem as relações capital-trabalho nos diferentes momentos da produção, da circulação, da distribuição e do consumo. Deve-se igualmente considerar a particularidade como sendo, segundo Marx, a expressão lógica da categoria de mediação entre o específico (singular) e o geral (universal), que, não podem ser compreendidos de modo isolado e por si mesmos.

A rotação do capital, em múltiplas escalas geográficas, visa invariavelmente às condições para a sua reprodução ampliada e de realização do excedente ou da mais-valia e produz, ao mesmo tempo, um processo de 
concentração e centralização do capital que caracteriza o desenvolvimento desigual e combinado e, portanto, definem e redefinem continuamente as escalas geográficas em suas magnitudes de abrangência e amplitudes relativas de coexistência de formas pretéritas (rugosidades) com movimentos contemporâneos ou potenciais.

No Livro III de O Capital (Volume 4) ao tratar da "lei" da tendência de queda da taxa de lucro, Marx (2013, p. 290) argumenta que

\begin{abstract}
O desenvolvimento da produção e da acumulação capitalistas leva a processos de trabalho em escala, em dimensões cada vez maiores, e, em consequiência, o desembolso crescente de capital para cada estabelecimento particular. Por isso, além de ser uma das condições materiais delas, é um dos resultados por elas produzidos a concentração crescente dos capitais, acompanhada, embora em proporção menor, de aumento do número dos capitalistas. Junto e em interação com isso, há a expropriação progressiva dos produtores diretos e indiretos. Fica, assim, compreensível a circunstância de capitalistas isoladamente considerados comandarem exércitos crescentes de trabalhadores [...] e a de aumentar a massa de mais-valia de que se apropriam e, por conseguinte, o montante do lucro, simultaneamente com a queda da taxa de lucro e apesar dessa queda.
\end{abstract}

Nesse sentido, o processo de valorização do espaço e do valor, ou a espacialização do valor, consiste igualmente em uma questão fundamental e nos impõe a necessidade de analisar o espaço em conexão com as particularidades históricas de formação social sob as determinações ontonegativas do valor. Porém:

A valorização do espaço, não se confunde imediatamente com outras manifestações da vida social, pois possui movimento próprio, elementos específicos que a caracterizam e resultados histórico-concretos particulares (MORAES; COSTA, 1984, p. 122).

Se o espaço constitui "uma condição universal e preexistente do trabalho", o valor do espaço consiste em uma qualidade natural intrínseca a sua própria condição material de valor de uso para qualquer forma social de produção. Dessa premissa inicial pode-se afirmar a especificidade dos processos de valorização capitalista do e no espaço em relação a outros modos de produção, a partir das determinações sociais da reprodução do capital sobre a 
renda absoluta, a renda diferencial (I), a renda monopólio, a circulação e, na esfera do mercado, sobre a concorrência.

Com a universalização da propriedade privada, o espaço assume o seu duplo valor: o valor de uso e o valor. Nesse sentido, a produção do espaço através da acumulação de trabalho e de fixação de valor ao solo, "define-se a possibilidade de um valor no espaço", pois não se trata somente do espaço como substrato material de existência ou como acumulação de trabalho morto, mas “do espaço no processo de trabalho, no nível imediato da produção. É a própria espacialidade do valor". Desse modo, o "valor no espaço diz respeito ao próprio espaço no processo de circulação" (MORAES; COSTA, 1984, p.128-131).

Entretanto, há uma prévia condição para que o processo de valorização no espaço se torne efetivo: a implantação da propriedade privada da terra.

\begin{abstract}
A história do capitalismo nada mais é, nesse sentido, que um processo histórico de privatização crescente de porções da superfície terrestre e de tudo o que ela contém. Sendo o consumo produtivo (e privado) do espaço o fundamento de sua valorização, a espoliação será uma tônica desse processo (MORAES; COSTA, 1984, p. 159-160).
\end{abstract}

Com efeito, a valorização do espaço como processo universal, apresenta a sua particularidade na construção dos territórios, estabelecendo mediações dialéticas entre o universal e o singular. Embora a valorização do espaço apresente um caráter universal, o capital opera uma verdadeira valorização seletiva do espaço. "Se o valor do espaço é desigualmente distribuído, também o valor no espaço manifesta-se em intensidade variáveis" (MORAES; COSTA, 1984, p. 167), pois a fixação de valor ao solo não mais se caracteriza pela sua extensividade, mas pela concentração intensiva nos lugares. Vale lembrar que a concentração dos meios de produção e centralização do capital são elementos intrínsecos ao desenvolvimento da produtividade do trabalho e do capital, daí o seu caráter seletivo.

A interpretação do caráter expansivo e seletivo do capital a partir da teoria da acumulação de Marx nos permite o aprofundamento da análise a respeito da circulação e da localização a partir da lógica expansionista do capital. Segundo Harvey, como já vimos acima com Marx (2005, p. 48): 
[...]a expansão geográfica para novas regiões, incrementando o comércio exterior, exportando capital e, em geral, expandindose rumo à criação do que Marx denominou o mercado mundial [ou seja] a expansão geográfica como produto necessário para o processo de acumulação.

A partir dessas primeiras considerações, a geografia histórica do capitalismo, na perspectiva da teoria marxista do valor, pode ser traduzida como sendo o processo de valorização do e no espaço a partir da unidade contraditória do movimento interno do valor constituído pelas relações capitaltrabalho sob as formas de concentração e centralização do capital e da força de trabalho.

Em outros termos a ótica peculiar da geografia possibilita um claro equacionamento da articulação entre a universalidade e a singularidade na expansão espacial desse modo de produção. Sua adaptabilidade à variação (natural e social) dos lugares defrontados constitui em si um eficaz mecanismo da dominação capitalista, no sentido em que a capacidade de inovação e de conviver com o diverso possibilitava a criação de estruturas específicas (no limite, singulares) que se integravam e reproduziam a lógica geral do sistema. Pode-se então falar de formas capitalistas de valorização do espaço e de uma valorização capitalista do espaço (MORAES, 2010, p. 16-17).

\section{METRÓPOLE: ESPAÇO E FETICHISMO}

Se a cidade possui uma existência antediluviana, a metrópole apresentase com um caráter específico decorrente do desenvolvimento do modo de produção capitalista. Se o capitalismo mundial de mercado é o parteiro da metrópole, esta se transforma, como em um feitiço, em sua própria genitora. A metrópole capitalista é o espaço imagem e semelhança do capital e, ao mesmo tempo, sua própria negação enquanto materialização de trabalho vivo que se opõe ao movimento de valorização do valor. Embora os edifícios, residências, ruas e praças estejam incrustadas ao solo, as formas em que assumem a sua circulação apresentam-se como determinações de sua própria espacialidade inerente a dimensão das relações de troca. 
A partir da concepção formulada por Henri Lefebvre acerca do espaço urbano, Odete Seabra (2011, p. 53) ${ }^{4}$ procura definir a metrópole a partir da síntese estabelecida pela conexão espaço-tempo:

A metrópole contemporânea é a síntese mais complexa da conexão espaço-tempo. Constitui-se num objeto privilegiado exatamente porque, nela, o tempo tem um fundamento social resultante do processo de divisão do trabalho e da generalização da economia de trocas. Na metrópole contemporânea à lógica (sistêmica) e a dialética (movimento/conflito) reúnem os elementos que qualificam o presente e que indicam o movimento da formação, o qual pode ser compreendido através de certas linhas (evolutivas) mais ou menos consistentes que demarcam a especificidade de processos urbanos particulares.

A especificidade dos processos urbanos, que se reproduzem em ritmos diferenciados, resulta tanto das formas de concentração e centralização do capital produtivo, quanto de sua base de dispersão decorrente de suas necessidades de expansão e de realização da mais-valia. Como condição de produção e realização de mais-valia, a metrópole torna-se uma imensa acumulação de "coisas" e homens, de mercadorias e de trabalho morto. A repetição que caracteriza a vida cotidiana do espaço metropolitano em sua reprodução infernal, não passa da mobilidade incessante do trabalho e do valor. A forma específica que o capital assume na configuração da metrópole faz dela um espaço da acumulação, dos negócios imobiliários, mas também do espetáculo das mercadorias e da miséria do trabalho. Como diria Guy Debord (1997, p. 21): "Toda a vida das sociedades nas quais reinam as modernas condições de produção se apresenta como uma imensa acumulação de espetáculos. Tudo o que era vivido diretamente tornou-se uma representação". Ou seja, a representação do mesmo, mas, sob o signo da novidade que se expõe no mercado como moda. A moda, como quer Benjamin, "tem um faro para o atual, onde quer que ele se oculte na folhagem do antigamente. Ela é um salto de tigre em direção ao passado" (2012, p. 249). Quanto à novidade, diz o autor: "é uma qualidade independente do valor de uso da mercadoria. Ela é a origem da aparência, inseparável, esta, das imagens produzidas pelo inconsciente coletivo" (BENJAMIN, 2006, p. 39).

4 Revista Geografares, ${ }^{\circ}$ 9, p.49 79, jul./Dez., 2011. Acesso: http://www.periodicos.ufes.br/geog rafares 
Inspirado em Feuerbach, Debord (1997, p. 24), assim define o espetáculo: "O espetáculo é a reconstrução material da ilusão religiosa. Assim é a vida mais terrena que se torna opaca e irrespirável. O espetáculo é a realização técnica do exílio dos poderes humanos em um além”. Da cidade à metrópole capitalista, o processo é sempre o de destruição do velho e de construção do novo. O seu motor é a economia política de mercado. A destruição e a proliferação de formas "novas" é o seu método próprio de valorizar-se. Nesse sentido, como argumenta Olgária Chain Féres Matos (2010, p. 154), "As metrópoles encontram-se em constante e acelerada transformação; a destruição dos espaços da cidade converte-a em metrópole impessoal e sem memória”.

Marx, em suas passagens por Londres e Paris em meados do século XIX, já havia notado que:

Qualquer observador desprevenido percebe que, quanto maior a centralização dos meios de produção, tanto maior o amontoamento correspondente de trabalhadores no mesmo espaço e, portanto, quanto mais rápida a acumulação capitalista, tanto mais miseráveis as habitações dos trabalhadores. Os "melhoramentos" urbanos que acompanham o progresso da riqueza, a demolição de quarteirões mal construídos, a construção de palácios para bancos, lojas, etc. [...] - desalojam evidentemente os pobres, expulsando-os para refúgios cada vez piores e mais abarrotados de gente (2017, p. 772).

No Capítulo 23 do Livro I de O Capital, quando trata da "lei geral da acumulação capitalista", Marx apresenta uma série de relatórios referentes às condições precárias habitacionais e de saúde da população trabalhadora, revelando como o espaço urbano tornou-se objeto de políticas urbanas, da especulação imobiliária, do luxo e da miséria. O quadro dramático das cidades industriais de meados do século XIX apresentado por Marx, ganhou traços muito mais marcantes no contexto da metrópole capitalista dos séculos XX e XXI. Se a metrópole, como diz Benjamin, é a aparência estranhada da modernidade, é porque sob a forma mercadoria ela é, para a classe dominante, apenas a antessala dos negócios urbanos.

Em Fisiognomia da Metrópole Moderna: representação da história em Walter Benjamin, ao analisar a relação entre Benjamin e Baudelaire sobre a metrópole moderna, W. Bolle (2000, p. 43) apresenta outro aspecto 
fundamental da concepção de Benjamin sobre a metrópole, isto é, a "produção de imagens".

A imagem é a categoria central da teoria benjaminiana da cultura: alegoria, imagem arcaica, imagem de desejo, fantasmagoria, imagem onírica, imagem de pensamento, imagem dialética. Assim, o corpo em que o fetichismo alienante das imagens se sobrepõe consiste, por sua vez, em outra imagem, a imagem dialética por excelência: Flâneur (BOLLE, 2000, p. 67).

O “corpo" da metrópole, se assim podemos expressar, carrega múltiplas imagens que, em seu fundo vazio, reflete a si mesmo, ora como a novidade que se sobrepõe ao arcaico, ora como o arcaico reveste-se de novidade e apresentase como moda. Essa profusão de imagens idílicas e infernais é, ao mesmo tempo, a sua manifestação como negócio e como espetáculo, onde o morto se acopla no vivo, fazendo deste último apenas o seu suporte orgânico para a sua realização como valor.

"Na paisagem urbana”, diz Olgária Matos (2010, p. 223):

[...] não é mais possível diferenciar realidade e ficção, modelo e reprodução, fato e direito. A partir de Marx, um dos mecanismos principais do fenômeno do fetichismo da mercadoria é a impossibilidade de o sujeito apreender a estrutura social da determinação do valor dos objetos em virtude de um regime de encantamento por sua visibilidade absoluta, sua suposta objetividade. Efetivamente, o fetichismo produz aparência - mercadorias -, inclusive a mercadoria visual que, como toda mercadoria, é objetividade fantasmática [...] daquilo que aparece. Trata-se da falsa objetividade da aparência, da facticidade de um estado falso, de um mundo objetivado, reificado.

Os edifícios corporativos que surgem nas metrópoles contemporâneas são exemplos desse espetáculo onírico em um mundo de pesadelos. Como diria Marx, a plumagem da ave, nem de longe, diz o que ela realmente é. A condição de sua emergência é o predomínio do capital fictício, o seu móvel redentor é o capital a juros, a sua fórmula reificada é D-D'. “O capital é agora coisa, mas como coisa capital. Esteja dormindo ou acordado, em casa ou em viagem, de dia ou de noite [...] realiza-se [como] capital portador de juros" (MARX, 1986, p. 295). 
A exposição dos conceitos e das práticas que acompanham e representam o modo distorcido das relações humanas sob a lógica e a dinâmica da sociedade capitalista, mostra que mesmo a descrição dos traços mais gerais da metrópole capitalista aponta para o "amontoado de ruínas" que constitui o "mundo dos homens e do capital" e o acelerado "progresso da catástrofe".

\section{FETICHISMO E FANTASMAGORIA}

O fetichismo da mercadoria, a reificação das relações sociais de produção e consumo veiculados pelo valor e, sobretudo, a mistificação das imagens dos desejos encarnadas na dissonância da repetição do mesmo, cujo sentido é o progresso da catástrofe, assumem na concepção de Walter Benjamin, a sagração do reino das mercadorias, portanto, o das fantasmagorias. Se o conceito de fetichismo guarda estreita relação estética com o de mercadoria, tanto na esfera da produção como na esfera do consumo, a fantasmagoria remete, por sua vez, tanto aos agentes e sujeitos do processo de acumulação de capital, quanto às relações sociais que produzem imagens de si mesmas mediante uma obscura consciência que busca justificar a sua existência e sua reprodução.

Se as noções de fetichismo e fantasmagoria são anteriores a emergência do capitalismo da chamada "grande indústria" e das tecnologias contemporâneas, somente com o desenvolvimento das mesmas em sua sociabilidade reificada é que essas noções passam a constituir os nexos das relações sociais em forma "pseudo-concreta" e aparentemente natural. Contudo, a condição essencial para que esse processo social se torne efetivo em sua expressão histórica e geográfica, é necessário que as categorias do capital estejam plenamente desenvolvidas, isto é, que a relação entre capital-trabalho seja, em sua totalidade, uma relação simultânea de expropriação e apropriação. Ou seja, que a divisão social do trabalho e as determinações da propriedade estejam subsumidas efetivamente ao processo de valorização do capital e desvalorização da força de trabalho.

Em O Rendimento e suas Fontes - a economia vulgar, Marx nos mostra como o desenvolvimento do modo de produção capitalista é, igualmente, acompanhado pela reificação das relações sociais e sua expressão fetichista como relações entre coisas. Nas palavras do autor: 
A forma e as fontes do rendimento (revenue) exprimem as relações da produção capitalista sob a forma mais fetichista. Sua existência, como surge na superfície, isola-se de suas conexões ocultas e dos elos intermediadores. Assim a terra se torna fonte de renda fundiária, o capital, a fonte do lucro, e o trabalho, do salário. A forma distorcida em que se expressa a inversão efetiva se encontra naturalmente reproduzida na representação dos agentes deste modo de produção. Este é um modo de ficção sem fantasia, uma religião do vulgar (1974, p. 267).

Em relação ao capital que rende juros, Marx faz a seguinte observação:

De todas essas formas, entretanto, o capital a juros constitui o fetiche mais completo. Encontramos aqui o primeiro ponto de partida do capital - o dinheiro - e a fórmula D-M-D', reduzida aos seus extremos D-D'. Dinheiro que cria mais dinheiro. É a fórmula mais originária e geral do capital concentrada num resumo sem sentido [...]. Este é o capital acabado - portanto, unidade do processo de produção e do processo de circulação que, por isso, num determinado período de tempo traz um determinado lucro [...]. No capital a juros se completa esse fetiche automático, de um valor que se valoriza a si mesmo, de um dinheiro que faz dinheiro, de sorte que, nesta forma, não traz mais o estigma de seu nascimento. A relação social se completa como relação da coisa [dinheiro, mercadoria] consigo mesma (1974, p. 267-268).

Mas isso não é tudo. "A mistificação das relações do capital decorre de que todas as partes dele aparecerem igualmente como fonte do valor excedente (lucro)” (MARX, 2013, p. 63). É nesse sentido, e concordando com Marx, que Grespan argumenta em $O$ Negativo do Capital, que:

A importância [...] do fetichismo na teoria de Marx reside em indicar como as relações sociais burguesas, desde suas formas mais simples, aparecem como forças externas, regidas por lei próprias (2012, p. 50).

No Livro I de O Capital, no famoso capítulo "O caráter fetichista da mercadoria e seu segredo", Marx argumenta que: "O caráter misterioso da forma-mercadoria consiste, portanto, simplesmente no fato de que ela reflete aos homens os caracteres sociais de seu próprio trabalho”. O trabalho, em sua expressão abstrata como mercadoria e trabalho privado assume, assim, uma dupla aparência, isto é, como objetivação da força de trabalho que visa a 
satisfação de uma necessidade social e, ao mesmo tempo, como algo equivalente e permutável. Desse modo, diz Marx, os produtores:

[...] equiparam entre si seus produtos de diferentes tipos na troca, como valores, eles equiparam entre si seus diferentes trabalhos como trabalho humano. Eles não sabem disso, mas o fazem (2013, p. 147-149).

A partir das análises desenvolvidas por Marx sobre as metamorfoses da mercadoria e do dinheiro, assim como do conceito de alienação de Karl Korsch, é que Walter Benjamin inicia seu projeto de pesquisa sobre as relações que caracterizam a alienação, o fetichismo e as formas fantasmagóricas das relações de troca. Naturalmente, são tantas outras referências utilizadas pelo autor ao longo da "montagem" de seus escritos que não cabe aqui examiná-las, mesmo na forma mais geral.

Em relação ao fetiche do dinheiro, Benjamin mostra como as suas funções nas relações de troca fazem com que ele apareça ora como um signo de si mesmo, mas, ao mesmo tempo, um não-signo, pois, concretamente é um dos resultados das metamorfoses da mercadoria. Vale acrescentar, de acordo com Grespan (2015, p. 53), que, em relação ao dinheiro, “o caráter de signo está mais desenvolvido e numa forma mais adequada, pois é equivalente a qualquer mercadoria”. A figura desenvolvida do dinheiro-capital, não altera apenas a velocidade de rotação do capital e seus vários ciclos, altera igualmente os processos de valorização do valor e, por conseqüência, a valorização do espaçomercadoria, pois, consiste na combinação de mecanismos de acumulação que "inclusive à terra ou os terrenos urbanos, que em si não são produto de trabalho humano, não têm valor, mas têm preço".

Do fetichismo do dinheiro, precede ao da mercadoria, onde as relações sociais reificadas estão plasmadas nos objetos de consumo, e estes possuem prazos de validade cada vez mais curtos e cujo desaparecimento é impulsionado, sobretudo, pela moda. Nesse sentido, Benjamin define a natureza do fetiche da mercadoria como o "conflito com o orgânico. Ela acopla o corpo vivo ao mundo inorgânico. No vivo, percebe os direitos do cadáver. O fetichismo, que subjaz ao sex appeal do inorgânico, é o seu nervo vital” (BENJAMIN, 1983, p. 51). 
A relação do inorgânico com o orgânico - das coisas que tomam o lugar das pessoas no mercado; do capital como trabalho morto nos meios de produção que suga o trabalho vivo do assalariado - é o domínio do mundo humano por uma segunda natureza que dele se destaca. E a relação do morto com o vivo, também aí presente, consiste nos direitos do cadáver, do que deve perecer para ser substituído pela novidade trazida pela moda; daí o sex appeal do inorgânico numa quase necrofilia. Daí, inclusive, mais um retorno da "alegoria barroca, que acunha numa cara - não, numa caveira o tempo natural como o da morte, e não o da transfiguração numa outra vida” (BENJAMIN apud GRESPAN, 2015, p. $56)$.

Embora o fetichismo, como vimos, possua uma existência anterior ao capitalismo5, somente na sociedade produtora de mercadorias ele se torna inerente as relações sociais, mas não para revelar como de fato ela é, mas como se representa a si mesma a partir da abstração do modo como ela produz e reproduz objetivamente a sua existência. De acordo com Grespan (2015, p. 5657), "A imagem que ela assim produz de si e que costuma designar como sua cultura corresponde [para Benjamin] ao conceito de fantasmagoria”.

Na interpretação de Dias (2015, p. 64):

O que interessava a Benjamin na cultura era principalmente sua superfície, seu lado externo, sua expressão mimética, que continha ao mesmo tempo ilusão e promessa, sonho e desejo.

Assim, de acordo com Dias (2015, p. 66-67), Benjamin definia as fantasmagorias:

[...] como mistificações que assumiam a aparência das imagens de desejo com as quais o coletivo procurava tanto superar quanto transfigurar as imperfeições do produto social bem como as deficiências da ordem social de produção. Elas eram fruto da interação entre o moderno e o antigo, entre o novo e o sempre igual acumulado pela experiência destas sociedades em seu inconsciente coletivo. A fantasmagoria expressa uma repetição cíclica, o eterno retorno do mesmo, mascarados

\footnotetext{
5 Os dicionários registram o ingresso da palavra fetiche nas línguas européias do século XVIII pelo português (feitiço). Por ocasião do empreendimento da conquista portuguesa, no século XVI, factcius conhece um renascimento e chega ao alemão faktisch, de onde vem fetichismus utilizado por Marx. MATOS, O. C. F. Benjaminianas - cultura capitalista e fetichismo contemporâneo. São Paulo: Editora Unesp, 2010, nota 13, p. 139-140.
} 
ilusoriamente como novidade representada infatigavelmente pela moda, sua agente infatigável.

A repetição claudicante e diabólica do mesmo, mas com a aparência de novidade revestida pela técnica transfigurada em "estética da mercadoria", isto é, na estética do sex appeal do inorgânico, mostra que o fetichismo não é mera ilusão sobre a realidade, mas a inversão própria da realidade social. Nesse sentido, a expressão fantasmagórica da sociabilidade ontonegativa do valor aparece, portanto, como a sua própria negação, isto é, como "cultura" da sociedade produtora de mercadorias.

De acordo com a interpretação de Fabio Mascaro Querido (2013, n/p.), a análise desenvolvida por Benjamin sobre o fetichismo, reificação e fantasmagoria:

[...] está ligada a uma forma específica de representação da ordem burguesa [...]. A questão do fetichismo é transformada em forma de representação (alegórica) própria da sociedade produtora de mercadorias em suas múltiplas dimensões".

Nas palavras de Benjamin, as criações da "cultura” se manifestam como fantasmagorias, pois, "tais criações sofrem esta iluminação não somente de maneira teórica, por uma transposição ideológica, mas também na imediatez da presença sensível. Manifestam-se enquanto fantasmagorias” (2006, p.53-54).

Para Querido (2013, n/p):

Benjamin sustenta que a cultura da sociedade produtora de mercadoria, isto é, a imagem que ela produz de si mesma, corresponde ao conceito de fantasmagoria, já que, entre outras coisas, esta imagem oculta a lembrança da forma como as mercadorias surgiram. É neste sentido que as mercadorias, enquanto objeto de consumo, transformam-se em "objetos mágicos" que, mais do que apenas revelar uma reificação do produtor em relação ao objeto produzido, eleva-se como representação fetichizada da própria cultura hegemônica em suas variadas formas de expressão concreta.

As considerações gerais até aqui apresentadas, mas que, sem dúvidas, exigem aprofundamentos teóricos e longa maturação intelectual para que a exposição da complexidade dos conceitos de fetichismo e fantasmagoria se dê de forma adequada ao processo social que pretende dar cabo numa perspectiva 
geográfica de análise da espacialidade do capital, cumpre o papel importante para a investigação em torno da valorização capitalista do espaço-mercadoria na medida em que elucida as formas de materialização e representação dos processos reais de produção, circulação, consumo, enfim, de acumulação de capital. Se o espaço não é uma intuição pura, como queria Kant, e, tampouco uma planície isotrópica, homogênea e vazia, mas uma condição de produção e força produtiva ele é, ao mesmo tempo, objeto de representações reificadas que se expressam como fantasmagorias. A metrópole constitui o exemplo mais significativo do que podemos entender por espaço-mercadoria e também do "progresso da catástrofe", onde as formas de dominação do capital e de "redenção dos oprimidos" se apresentam transfiguradas em imagens que procuram ocultar a supremacia do "reino das mercadorias".

As análises sobre a metrópole capitalista e as formas de fantasmagorias, são ainda de caráter aproximativo. Os estudos realizados no âmbito da geografia, cuja metrópole se constitui objeto, guardam uma dimensão temática que foge inteiramente do escopo deste pequeno artigo. Se considerarmos, ainda, as pesquisas nas áreas de arquitetura e urbanismo, economia e política urbana, tornam-se ainda mais difícil contemplar as variadas abordagens acerca das múltiplas faces da metrópole contemporânea. Assim, o que podemos obter de mais efetivo em relação aos limites desta síntese são proposições de uma agenda de pesquisa que venha dar uma contribuição teórica e metodológica para o estudo da metrópole e suas formas fantasmagóricas como expressão da "cultura capitalista".

\section{CONSIDERAÇÕES FINAIS}

A mercadoria, como unidade de valor, é também a síntese de múltiplas determinações, portanto, unidade de concreção das relações de produçãocirculação. Se partirmos de imediato do valor acarretará a supressão do essencial do conceito e, igualmente, as mediações necessárias a sua compreensão. Além disso, teremos de dar como assente os resultados históricos do processo de divisão social do trabalho, a separação das condições de existência dos produtores diretos e etc., a existência autônoma do dinheiro e da força de trabalho no processo de circulação e, invariavelmente, relativizar a 
importância das categorias que derivam do processo de acumulação primitiva do capital.

Todavia, coloca-se também como necessidade metodológica estabelecer, em última análise, a diferenciação conceitual em relação ao trabalho. Há uma diferença fundamental entre o:

[...] intercâmbio criador de valor de troca e o trabalho criador de valor de troca. No intercâmbio criador de valor de troca desenvolvem-se as primeiras categorias, supõe-se que as coisas trocadas são produtos do trabalho, mas o trabalho - na medida em que apenas seja trocado - não tem significado econômico. Apenas na passagem para o capital e no desenvolvimento da categoria lucro é que o trabalho adquire significado econômico: pois a categoria lucro (incluindo juros) coloca a pergunta sobre de onde vem a riqueza que é acumulada sob essa forma (REICHELT, 2011, p.76).

Essa distinção entre intercâmbio criador de valor de troca e a força de trabalho criadora de valor de troca, torna-se relevante porque permite, igualmente, a distinção entre valorização do espaço e valorização no espaço. Se no primeiro caso, os meios naturais tornam-se produtos sem a mediação da força de trabalho, mas por ser propriedade privada garantem de imediato a existência da renda monopólio; no segundo caso, somente mediante a fixação de trabalho vivo ao solo, isto é, produção e valorização no espaço, podem aludir sobre a dedução de juros e lucros.

Além desse aspecto relacionado ao trabalho, acreditamos também que foi crucial para a adequação dos nossos estudos em relação ao objeto A categoria capital fixo permite compreender a relação entre juro e sistema de crédito e sua conexão com as formas de circulação do capital fixo como um dos pressupostos da valorização capitalista no espaço.

\section{REFERÊNCIAS BIBLIOGRÁFICAS}

BENJAMIN, W. Obras Escolhidas - V. 2: Rua de mão única. Tradução:

Rubens R. Torres Filho e José Carlos M. Barbosa. São Paulo: Brasiliense, 1983. 
BENJAMIN, W. Passagens. Willi Bolle (Org.); Matos, O. C. F. (Col.). Tradução: Irene Aron e Cleonice P. B. Mourão. Belo Horizonte/São Paulo: Editora UFMG/Imprensa Oficial do Estado de São Paulo, 2006.

BENJAMIN, Walter. "Para uma crítica da violência", in: Escritos sobre mito e linguagem. São Paulo: Duas Cidades; Editora 34, 2012.

BOLLE, Willi Fisiognomia da Metrópole: representação da história em Walter Benjamin. São Paulo: Edusp, 2000.

DEBORD, G. A Sociedade do espetáculo. Rio de Janeiro: Contraponto, 1997.

DIAS, Wellington Durães As Exposições Universais e suas Fantasmagorias. WALTER BENJAMIN: experiência histórica e imagens dialéticas; Orgs. MACHADO, Carlos E. J.; MACHADO JR., Rubens; VEDDA, Miguel. São Paulo: Editora Unesp, 2015.

FOLEGATTI, Luiza G.; SCHIAVINATTO, Iara Lis F. As Cidades de Jacques Tati: novas relações sócio-técnicas presentes na década de 50. São Paulo: Codis História, Arte e Cidades, nº 6, jan./jun, 2011, p. 333-366.

GRESPAN, Jorge O Negativo do Capital - o conceito de crise na crítica de Marx à economia política. São Paulo: Expressão Popular, 2012.

GRESPAN, J. Fetiche e Alegoria. In: Machado, Carlos E. J.; Machado Jr., Rubens; Vedda, Miguel (Orgs.) Walter Benjamin - experiência histórica e imagens dialéticas. São Paulo: Editora Unesp, 2015, p. 51-58.

HARVEY, D. A Produção Capitalista do Espaço. Tradução: Carlos Szlak. São Paulo: Annablume, 2005

MARX, K. Manuscritos Econômico-Filosóficos e outros textos escolhidos. Tradução: José Carlos Bruni. Coleção: Os Pensadores. São Paulo: Abril/Cultural, 1974.

MARX, K. O Capital - crítica da economia política. Tradução: Regis Barbosa; Flávio R. Kothe. São Paulo: Editora Abril, Volume IV, 1986.

MARX, K. O Capital - Livro I - crítica da economia política: O processo de produção do capital. Tradução Rubens Enderle. São Paulo: Boitempo, 2013.

MARX, K. O Capital - Livro III - O Processo Global da Produção Capitalista. Tradução: Rubens Enderle. São Paulo: Boitempo, 2017.

MATOS, Olgária C. F. Benjaminianas: cultura capitalista e fetichismo contemporâneo. São Paulo: Editora Unesp, 2010. 
QUERIDO, Fabio Mascaro. Fetichismo e fantasmagorias da modernidade capitalista: Walter Benjamin leitor de Marx. Revista Outubro, 21. Disponível em: http: / /www.revistaoutubro.com.br/edicoes/21/out21_08.pdf.2013.s`

REICHELT, Helmut Que método Marx ocultou? Tradução: Luciano C. Martorano. Campinas: Crítica Marxista, $\mathrm{n}^{0}$ 33, 2011, p. 67-82.

SEABRA, Odete C. de L. Pensando o processo de valorização e a geografia. Boletim Paulista de Geografia, n. 66, 1988, pp. 97-103.

SEABRA, O. C. DE L. Revista Geografares, nº 9, p.49- 79, jul./Dez., 2011. Acesso: http://www.periodicos.ufes.br/geografares.

SEABRA, O. C. de L. Metropolização: a reprodução do urbano na crise da sociedade do trabalho. Presidente Prudente: Cidades, v. 6, $\mathrm{n}^{0}$ 10, 2009, p. 415433 .

Recebido em agosto de 2019

Aceito em setembro de 2019 